\title{
Diz çevresi peroneal sinir tuzak nöropatisi
}

\author{
Peroneal nerve entrapment at the knee
}

\author{
Egemen Turhan, Gazi Huri, Mahmut Nedim Doral
}

Hacettepe Üniversitesi Tıp Fakültesi, Ortopedi ve Travmatoloji Anabilim Dalı, Ankara

\begin{abstract}
Ortak peroneal sinirin fibula başı çevresinde tuzak nöropatisi, alt ekstremitenin en sık karşılaşılan mononöropatisidir. Peroneal sinirin fibula başı ile yakın komşuluğu, kompartmanları dar fibro-osseöz tünellerden değiştirmesi ve diz çevresinde yüzeyel seyretmesi, travmalara karşı zayıflığının anatomik nedenleri arasındadır. Bununla birlikte, çömelmenin ön planda olduğu sportif veya mesleki uğraşlar da peroneal sinirin tuzaklanmasına yatkınlık sağlamaktadır. Düşük ayak en belirgin semptom olmakla beraber, çoğu hastada klinik müphem ağrı ve duyu sorunları ile seyreder. Koruyucu veya cerrahi tedavi seçimini belirleyen en büyük etmen ise altta yatan etiyolojidir. Bu derlemenin amacı; peroneal siniri tuzak nöropatisinin patoanatomisi, etiyolojisi, klinik seyri, tanı yöntemleri ve tedavi yaklaşımlarını ele almaktır.
\end{abstract}

Anahtar sözcükler: peroneal sinir; sinir tuzaklanmaları; diz
Common peroneal nerve entrapment at the fibular head is the most common mononeuropathy at the lower limb. The anatomic reasons for vulnerability to injuries of peroneal nerve are the direct contact to the fibular head, shifting compartments from narrow fibroosseous tunnels, and superficial trace around knee. Nevertheless, there is propensity to nerve entrapment in individuals who is performing kneeling and squatting during sportive and occupational activities. Although drop foot is the most significant symptom, most of the patients suffer due to uncertain pain and sensation problems. Underlying etiology of the nerve entrapment is the most important determinant for treatment modality. The purpose of this review is discuss the pathoanatomy, etiology, clinical findings, diagnostic tools and treatment modalities of the peroneal nerve entrapment.

Key words: peroneal nerve; nerve entrapments; knee
P eroneal mononöropati, alt ekstremitenin en sık rastlanılan mononöropatisidir. Çoğunlukla, fibula başı ile olan yakın komşuluğunun akut travmalardan sonra peroneal sinirin yaralanmasına neden olduğu iyi bilinmektedir. Her ne kadar alt ektstremitenin en sık tuzak nöropatisi fibula başı çevresinde peroneal sinire ait olsa da, bunun cerrahi olarak dekomprese edilmesi çok sık başvurulan bir yöntem değildir. Bu derlemenin içeriğinde, diz çevresi peroneal sinir tuzak nöropatisi (PSTN)'nin patoanatomisi, etiyolojisi, tanısı ve ayırıcı tanısı ile tedavi yaklaşımları olacaktır.

Illk olarak 1921 yılında Sultan, peroneal sinirin diz çevresinde bir kist sonucunda felç olmasını rapor etmiştir. ${ }^{[1]} \mathrm{Bu}$ olgu bildirimini takiben, gangliyon kistine ikincil diz çevresi PSTN, bazı yazarlar tarafından kaleme alınmıştır. ${ }^{[2-4]}$ Doğrudan sinire bası yapan kitlelerin dışında, literatürde ilk olarak Noble tarafından, ayak bileği inversiyon yaralanması sonrasında diz çevresinde oluşan vaso nevrosum kaynaklı hematomun siniri sıkıştırdığı bildirilmiştir. ${ }^{[5]}$ Bu olguların ardından literatür, iskemik etiyolojiye, sıkışma mekanizmalarına ve idiyopatik nedenlere odaklanmıştır. ${ }^{[6-11]}$

Peroneal siniri, tuzak nöropatiye yatkın kılan önemli nedenler arasında, bu sinirin fibula başı ile doğrudan temas etmesi, yüzeysel seyretmesi ve diz çevresinde kompartman değiştirmesi nedeniyle gerim kuvvetlerine karşı yeterli mobilizasyon özelliğinin olmamasıdır.

\section{ANATOMi}

Peroneal sinirin, birincil sinir kökü L5 olmakla birlikte, L4-S2 sinir arasına yayılan geniş bir başlangıç noktası mevcuttur. Peroneal sinir, tibial sinir ile birlikte

- Iletişim adresi: Doç. Dr. Egemen Turhan, Hacettepe Üniversitesi Tıp Fakültesi Ortopedi ve Travmatoloji Anabilim Dalı, Altındağ, Ankara Tel: 0312 - 3051209 e-posta: egemen.turhan@hacettepe.edu.tr

- Geliș tarihi: 13 Ekim $2015 \quad$ Kabul tarihi: 13 Ekim 2015 
siyatik sinirin bir parçası olarak ilerler ve popliteal boşluk proksimalinde ayrılmaya başlar. Diz eklemi seviyesine kadar, sadece biseps femoris kasının kısa başına motor dallar verir. ${ }^{[12]}$ Popliteal çukurda ilk duyu dalı olan sural sinir, tibial sinirden de lifler alarak ayrilır ve baldır-ayak lateralinin duyusunu sağlar. Peroneal sinirin, fibula başını ve boynunu dönerek kemiğin periostiumu ile $10 \mathrm{~mm}$ boyunca direkt teması vardır ve $4 \mathrm{~cm}$ boyunca subkutanöz seyreder. ${ }^{[13]}$ Fibula başı ile bu direkt ve yüzeyel ilişki, sinirin hem travmalar hem de dıştan sıkıştıran oluşumlar karşısındaki hassasiyetinin en önemli nedenidir. Peroneal sinir, fibula başından döndükten sonra, peroneus longus orijini ve intermusküler septum tarafindan oluşturulan fibroosseöz bir tünelden geçerek, yüzeyel ve derin olmak üzere iki dala ayrılır. Derin peroneal sinir, ilk tünelin 4 $\mathrm{cm}$ kadar distalinde ve anteriorunda, çatısını ektansör dijitorum longus kasının oluşturduğu ikinci bir tünele girerek, anterior kompartmana geçer. Derin peroneal sinir, anterior kompartmanda yer alan tibialis anterior, ekstansör hallusis longus, ekstansör dijitorum longus ve peroneus tertius kasını innerve eder. Distalde ayak çevresinde ise ekstansör hallusis brevise ve ekstansör dijitorum brevise motor dalları verirken, sadece 1. web aralığında (webspace) duyu dalı bulunur. ${ }^{[11]}$ Yüzeyel peroneal sinir ise peroneus longus ve brevisin motor innervasyonu ile ayak sırtı ve baldır lateralinin duyusunu sağlar. Önemli bir anatomik varyasyon da, yüzeyel peroneal sinirden çıkan aksesuvar peroneal sinirdir. Bu sinir, toplumun üçte birinde görülür ve ekstansör dijitorum brevis kasını innerve eder. ${ }^{[14]}$

Derin peroneal sinir felcinde; düşük ayak (stepaj yürüyüş) ve 1 . web aralığında duyu kaybı olur. Ayakta evertör ve plantar fleksörler arasındaki dengesizlik sonucunda, ayakta ekinus ve valgus gelişir. Yüzeyel peroneal sinir felci sonrasında ayak invertörlerinin hakimiyet kazanması sonucunda, ayakta varus gelişir ve ayak sırtı ile baldır lateralinde duyu kaybı olur.

Peroneal sinirvasküler açıdan da zayıftır. Sunderland, yaptığı çalışmada, bu sinirin popliteal çukurda bir tek nütrisyonel arterinin varlığını ortaya koyabilmiştir. Buna karşılık tibial sinir, vasküler ağ açısından peroneal sinire göre çok daha zengindir. ${ }^{[15]}$

\section{ETIYOLOJi}

Peroneal sinir felci; laserasyon, kontüzyon, kompresyon, traksiyon, iskemi, nöropati, tümör, ve idiyopatik nedenler sonrasında gelişebilir. Bu grupta, iyatrojenik nedenlerin de göz ardı edilmemesi gerekir. ${ }^{[13]}$

Anatomik olarak, peroneal sinirin fibula başı ile doğrudan komşuluğu ve yüzeyel yerleşimi, travmalar karşısında yaralanmaya olan yatkınlığını açıklayabilir.
Bu bölgedeki fibula başı kırığı veya eklem dislokasyonu sonrası, direkt travmalar ve laserasyonlarla, sinir doğrudan yara alabilir. Ayak bileğinin aşırı fleksiyon ve inversiyon yaralanmaları sonrasında da peroneal sinir felcine rastlanılmıştır. Bu yaralanma mekanizması ile, sinirin nütrisyonel arterinin gerilmesine ikincil iskemi oluştuğu görüşü ileri sürülmüştür. ${ }^{16]}$

Peroneal nöropatinin en sık rastlanılan nedeni ise sinirin dışarıdan bası altında kalmasıdır. Sürekli bacak bacak üstüne atmak veya bir bacağı diğerinin altına alarak oturmak ya da sürekli çömelerek iş yapmak, sinirin sıkışmasına neden olabilir. Bunu, Anglosakson literatürü 'Çilek Toplacısı Felci' olarak adlandırmıştır. ${ }^{[17]}$ Chusid, Yoga sporu yapanlarda, virasana posizyonu olarak bilinen, uzun süreli dizlerin üzerinde topuk üstüne oturma sonucunda, bilateral peroneal sinir felcini rapor etmiştir. ${ }^{[18]}$ Aslında bu oturma şekli toplumuzda namaz kılma sırasında sıkça yapılmasına rağmen, Yoga ile kıyaslandığında, kısa süreli olduğundan ötürü sinir hasarına neden olmamaktadır. Dışarıdan bası nedenlerinin biri de, mesleki, sportif veya sağlık amaçlı olarak, sürekli sıkı dizliklerin kullanılmasıdır. ${ }^{[1]]}$ Dizi geçen alçı, atel ve cilt traksiyonu uygulamaları sonrasında da sinir bası altında kalabilir. Anterior kompartman sendromu ise, izole derin dalının felci ile sonuçlanır.

Hızlı kilo kaybı, aşııı alkol tüketimi, diabetes mellitus ve malnütrisyon da peroneal sinir felci nedenleri arasında yer almaktadır.

Daha nadir nedenler arasında, Baker veya diğer gangliyon kistleri, aşırı kallus oluşumu ve nöromalar sayılabilir. Mangeri ve Yamahiro, diz travması sonrasında deforme şekilde iyileşmiş fabellanın sinir basısı yaptığını göstermişlerdir. Şikayetler, fabellanın eksizyonu sonrası gerilemiştir. ${ }^{[19,20]}$ Gangliyon kisti, ilk tanımlanan dıştan bası nedenidir ve günümüze kadar sinirin kendi dokusundan peroneus longus tendonuna kadar uzanan çeşitli çıkış yerlerinin sinire bası yaptığı gösterilmiştir. ${ }^{[21]}$ En sık proksimal tibiofibular eklemden köken alan kistlerin, eklemin duyu dalı boyunca, peroneal sinire ulaştığı görülmüştür. ${ }^{[22]}$ Erdil ve arkadaşları da, sinoviyal kistin neden olduğu diz çevresi peroneal sinir felcini rapor etmişlerdir. ${ }^{[23]}$ Kronik lateral ayak bileği instabilitesi sonrasında da peroneal güçsüzlük nadir değildir ve olası hipotezlerden biri de peroneus longus tendonun mikrotraksiyonu ile sinirin kronik bası yaralanmasına maruz kalmasıdır. ${ }^{[23,24]}$

\section{KLINIK VE BULGULAR}

PSTN olgusunun en önemli klinik bulguları, tam veya kısmi düşük ayak ile birlikte ayak bileği dorsifleksörlerinin ve evertörlerinin zayıflı̆̆ıdır. Semptomlar etiyoloji ile birlikte değişiklik göstermekle beraber; hastaların 
öncelikli yakınmaları, ağrı, duyu ve güç kaybıdır. Klinik özellikler arasında, anterior kompartman tutulumu laterale göre daha ön plandadır. Anterior kompartman kasları arasında ise en çok eksstansör hallusis longus etkilenir ve en son geri döner. ${ }^{[11]}$ Hastaların, ayaklarının takılmasını engellemek için kalça ve dizlerini fleksiyona getirerek yürümeleri tipiktir (stepaj yürüyüş). Baldır lateralinde ve ayak dorsumunda duyu kaybı olabilir. Fibula başı çevresinde, perküsyon sonrasında hassasiyet ve Tinel bulgusu olabilir.

\section{AYIRICI TANI}

L4-5 seviyesinde yer alan ve L5 sinir kökünün birincil olarak etkilendiği disk hernilerinde, ortak peroneal sinir tuzak nöropatisini taklit edebilir. Ayırıcı tanıda, peroneal sinirin innerve ettiği kas gruplarının zayıflı̆̆ı yanında, tibialis posterior kasının da gücü zayıflamış ise sorunun adresi olarak lomber vertebraya yönelmek gerekir. ${ }^{[25]}$

\section{TANI TESTLERi}

Geçirilmiş olan travmalar sonucunda ortaya çıkan artritik değişikler, deformiteler ve anormal kallus varlığı, direkt grafiler ile değerlendirilebilir. ${ }^{\left[{ }^{[, 19]}\right.}$ Fibula başı çevresindeki yapısal değişiklikler veya eksositoz gibi tümöral gelişimler de ilk olarak direkt grafi ile değerlendirilir. Manyetik rezonans (MR) görüntüleme, fibula başı çevresindeki kistik oluşumları ve solid kitlelerin ayırıcı tanısı açısından yardımcı olabilir. ${ }^{[26,27]}$

\section{ELEKTROMIYOGRAFI (EMG)}

Sinir iletim çalışmaları, peroneal sinir lezyonunun lokalizasyonunu saptamada yardımcıdır. Birçok teknik tanımlanmış olmakla beraber, temel olarak değerlendirilen 2 parametre vardır: amplitüd ve iletim hızı. Bu iki parametre kendi aralarında değerlendirildiğinde, amplitüd daha hassas gözükmektedir. ${ }^{[28]}$ Bunun nedeni, sinirin kısmi aksonal hasarında halen iletim hızı normal olmakla beraber, amplitüdün düşmesidir. Pickett, \%20 motor amplitüd düşmesinin sinir disfonksiyonu için yeterli olduğunu rapor etmiş ise de, bu oranın \%75 olduğunu savunan araştırmacılar da vardır. ${ }^{[28,29]}$

Sinir iletim çalışmalarının çoğu, peroneal sinirin ekstansör dijitorum brevise motor iletisinin üzerinden yapılır. Bu çalışma, hem fibula başı proksimalinden hem de distalinden tekrar edilerek, tuzak nöropatinin yeri saptanmaya çalışılır. Kasın direkt travma ile denerve olması, distal nöropatiler ve aksesuvar peroneal sinir varlığı da göz önüne alınmalıdır. ${ }^{[17]}$ Bütün çalışmalar, karşılaştırma amaçlı bilateral olarak yapılmalıdır.

Yüzeyel peroneal sinirin duyusal yanıtının azalmış olması, dorsal kök gangliyonunda lezyon olabileceğine işaret eder. Tibial motor iletim, F-yanıt ve sural sinir çalışmaları ile, pleksopati, siyatik sinir sorunları ve periferal nöropatilerin ayırıcı tanısı yapılabilmektedir (Tablo 1). İğne EMG ile, lezyonun yeri ile düşük ayağa neden olabilecek pleksopati ve kök basısı gibi diğer sorunların ayırımı yapılabilir. Peroneal sinirin fibula başı proksimalinde tek innerve ettiği kas olması nedeniyle, biseps femoris kasının kısa başı, lezyonun yerinin saptanması açısından iyi bir yol göstericidir. ${ }^{[17]}$

\section{TEDAVI VE PROGNOZ}

Diz çevresi PSTN tedavisi ele alınırken, etiyolojik nedenler göz önünde bulundurulmalıdır. Dışarıdan bası yapan nedenler ile alışkanlıklar, sportif ve mesleki aktiviteler iyi sorgulanmalıdır. Bu grup hastalarda, öncelikli olan konservatif tedavidir. i̇çten bası yapan kitleler veya doğuştan ve edinsel anatomik farklılıkların varlığında ise, sinirin cerrahi olarak gevşetilmesi ve/veya nöroliz işleminden hastalar daha çok yarar görür.

Baron, idiyopatik tuzak nöropati sonucunda gelişen düşük ayak tedavisi için koruyucu tedaviyi savunmaktadır. Bu hasta grubunda, risk faktörlerinin ortadan

Tablo 1. Düşük ayak değerlendirmesinde sinir iletim hızı çalışmaları ${ }^{[17]}$

\begin{tabular}{|c|c|c|c|c|}
\hline Lezyon & Yüzeyel peroneal duyu & Sural duyu & Tibial motor & Peroneal motor \\
\hline L5 radikülopati & $\mathrm{N}$ & $\mathrm{N}$ & N & $\downarrow N \mathrm{NH}$ \\
\hline Siyatik & $\downarrow$ & $\downarrow$ & $\downarrow N \mathrm{IH}$ & $\downarrow N \mathrm{NH}$ \\
\hline OPS & $\downarrow$ & $\downarrow$ & N & $\downarrow$ \\
\hline DPS & $\mathrm{N}$ & N & N & $\downarrow N \mathrm{NH}$ \\
\hline YPS & $\downarrow$ & $\mathrm{N}$ & $\mathrm{N}$ & $\mathrm{N}$ \\
\hline
\end{tabular}

$\mathrm{N}$, normal; iH, iletim hızı; OPS, ortak peroneal sinir; DPS, derin peroneal sinir; YPS, yüzeyel peroneal sinir. 
kaldırılması, uygun bir rehabilitasyon terapisinin planlanması ve düşük ayak için splint kullanılmasını önermiş;:[30] ayrıca, fibula başı çevresi yumuşak destekler kullanılarak sinirin korunması ve lokal glukokortikoid enjeksiyonlarının da yararlı olduğunu belirtmiştir. Uzenot, altı ay boyunca uygulanan koruyucu tedaviye yanıt vermeyen hastalara cerrahi planlanmasını önerirken; Dallari ise, neden ne olursa olsun hızlı ve tam iyileşme için mümkün olduğunca erken cerrahi gevşetme önermektedir. ${ }^{[31,32]}$

Diz çevresi sinir basısına neden olan kitlelerin varlığında, öncelikli olarak cerrahinin düşünülmesi gerekmektedir. ${ }^{[33]} \mathrm{Bu}$ hasta grubunda, kitlenin eksizyonu sonucunda daha hızlı geri dönüş olduğu iyi bilinmektedir. Artiküler kistler aspire edilmelidir. Intranöral kistlerin varlığında ise, kist eksizyonu ile birlikte intrafasiküler nöroliz ve artiküler dalların ligasyonu önerilmektedir. ${ }^{[34]}$ Kitlelerin çıkarılma zamanı ile ilgili literatürde net bir bilgi olmamakla beraber, Stack, dört ay içerisinde çıkarılmasının motor fonksiyonun kazanımında daha etkili olduğunu belirtmiştir. ${ }^{[35]}$ Yüzeyel peroneal tuzak nöropatisinde ise, peroneal tünelin gevşetilmesinin sonuçları, özellikle sporcu hasta grubunda daha yüz güldürücüdür. ${ }^{[36,37]}$

Traksiyon yaralanmalarında ise, tarihsel olarak çoğunlukla 'bekle ve gör' yaklaşımı hakimdi. Yaralanma sonrası altı ay içerisinde kısmi veya tam dönüş olmaması durumunda, cerrahi önerilmekteydi. ${ }^{[13,38]} \mathrm{Bu}$ genel görüş de güncel literatürde sorgulanmış ve ayak bileği inversiyon yaralanmaları sonrasında ve lateral ayak bileği instabilitesi zemininde gelişen PSTN olgularında, erken nöroliz sonuçlarının da iyi olduğu gösterilmiştir. ${ }^{[39,40]}$

Sonuç olarak; diz ve ayak bileği çevresinde gelişen ağrı, parestezi ve güçsüzlük şikayetlerinde, diz çevresi peroneal sinirin tuzaklanma ihtimalini göz önünde bulundurulmalıyız. Tanı ve tedavi algoritmamızı planlarken, kişisel alışkanlıkları ve olası etiyolojik faktörleri beraber değerlendirilmeliyiz. L5 sinir kökü lezyonları ile ayırıcı tanı konusunda farkındalığımız ve bu amaçla, klinik gözlem ile birlikte EMG tetkiklerini iyi yorumlamamız, tedavi başarısına doğrudan etki edecektir.

\section{KAYNAKLAR}

1. Sultan C. Ganglion der nervenscheide des nerves peroneus. Zentralbl Chir 1921;48:963-5..

2. Brooks DM. Nerve compression by simple ganglia. J Bone Joint Surg Br 1952;34-B(3):391-400.

3. Parkes, A. Intraneural ganglion of the lateral popliteal nerve. J Bone Joint Surg Br 1961;43-B:784-90.

4. Cobb CA 3rd, Moiel RH. Ganglion of the peroneal nerve. Report of two cases. J Neurosurg 1974;41(2):255-9.
5. Nobel W. Peroneal palsy due to hematoma in the common peroneal nerve sheath after distal torsional fractures and inversion ankle sprains. J Bone Joint Surg Am 1966;48(8):1484-95.

6. Myers RJ, Murdock EE, Farooqi M, Van Ness G, Crawford DC. A Unique Case of Common Peroneal Nerve Entrapment. Orthopedics 2015;38(7):e644-6. CrossRef

7. Yıldırım E, Sarıkaya IA, İnan M. Unusual entrapment of deep peroneal nerve after femoral distal extension osteotomy. J Pediatr Orthop B 2015;24(5):440-3. CrossRef

8. Çınar A, Yumrukçal F, Salduz A, Dirik Y, Eralp L. A rare cause of 'drop foot' in the pediatric age group: Proximal fibular osteochondroma a report of 5 cases. Int J Surg Case Rep 2014;5(12):1068-71. CrossRef

9. Beltran LS, Bencardino J, Ghazikhanian V, Beltran J. Entrapment neuropathies III: lower Limb. Semin Musculoskelet Radiol 2010;14(5):501-11. CrossRef

10. Marwah V. Compression of the lateral popliteal (common peroneal) nerve. Lancet 1964;2(7374):1367-9.

11. Garland $H$, Moorhouse D. Compressive lesions of the external popliteal (common peroneal) nerve. $\mathrm{Br}$ Med J 1952;2(4799)1373-8.

12. Wilbourn AJ. AAEE case report \#12: Common peroneal mononeuropathy at the fibular head. Muscle Nerve 1986;9(9):825-36.

13. Berry H, Richardson PM. Common peroneal nerve palsy: a clinical and electrophysiological review. J Neurol Neurosurg Psychiatry 1976;39(12):1162-71.

14. Preston DC, Shapiro BE. Peroneal nerve palsy. In: Preston DC, Shapiro BE, editors. Electromyography and neuromuscular disorders: clinical-electrophysiologic correlations, 3rd ed. London (UK): Elsevier/Saunders; 2013.

15. Sunderland S. Blood supply of the sciatic nerve and its popliteal divisions in man. Arch Neurol Psychiatry 1945;54:283-9.

16. Stewart JD. Foot drop: where, why and what to do? Pract Neurol 2008;8(3):158-69. CrossRef

17. Craig A. Entrapment neuropathies of the lower extremity. PM R 2013;5(5 Suppl):S31-40. CrossRef

18. Chusid J. Yoga foot drop. JAMA 1971;217(6):827-8.

19. Mangieri JV. Peroneal-nerve injury from an enlarged fabella. A case report. J Bone Joint Surg Am 1973;55(2):395-7.

20. Yamahiro K. Case of fibular nerve paralysis possibly caused by the fabella. Seikei Geka 1967;18(2):145-50.

21. Evans JD, Neumann L, Frostick SP. Compression neuropathy of the common peroneal nerve caused by a ganglion. Microsurgery 1994;15(3):193-5.

22. Muckart RD. Compression of the common peroneal nerve by intramuscular ganglion from the superior tibio-fibular joint. J Bone Joint Surg Br 1976;58(2):241-4.

23. Erdil M, Ozkan K, Ozkan FU, Bilsen K, Turkmen I, Senol S, Sarar S. A rare cause of deep peroneal nerve palsy due to compression of synovial cyst -case report. Int J Surg Case Rep 2013;4(5):515-7. CrossRef

24. Hyslop $\mathrm{GH}$. Injuries to the deep and superficial peroneal nerves complicating ankle sprain. Am J Surg 1941;51:436-8.

25. Hunter RE. Peroneal nerve entrapment at the knee. Operative Techniques in Sports Medicine 1996;4(1):46-53.

26. Dong Q, Jacobson JA, Jamadar DA, Gandikota G, Brandon C, Morag Y, Fessell DP, Kim SM. Entrapment neuropathies in the upper and lower limbs: anatomy and MRI features. Radiol Res Pract 2012;2012:230679. CrossRef 
27. Damarey B, Demondion X, Wavreille G, Pansini V, Balbi V, Cotten A. Imaging of the nerves of the knee region. Eur J Radiol 2013;82(1):27-37. CrossRef

28. Pickett JB. Localizing peroneal nerve lesions to the knee by motor conduction studies. Arch Neurol 1984;41(2):192-5.

29. Singh N, Behse F, Buchthal F. Electrophysical study of peroneal palsy. J Neurol Neurosurg Psychiatry 1974;37(11):1202-13.

30. Baron D. Prise en charge locale des syndromes canalaires. Rev Rhum 2007;74:424-33. CrossRef

31. Uzenot D, Cantiniaux S, Pouget J. Syndromes canalaires entre "hanches" et "pieds". Rev Rhum 2007;74:401-8. CrossRef

32. Dallari D, Pellacani A, Marinelli A, Verni E, Giunti A. Deep peroneal nerveparesis in a runner caused by ganglion at capitulum peronei. Case report and review of the literature. J Sports Med Phys Fitness 2004;44(4):436-40.

33. Maalla R, Youssef M, Ben Lassoued N, Sebai MA, Essadam H. Peroneal nerve entrapment at the fibular head: outcomes of neurolysis. Orthop Traumatol Surg Res 2013;99(6):719-22. CrossRef

34. Spinner RJ, Atkinson JL, Scheithauer BW, Rock MG, Birch R, Kim TA, Kliot M, Kline DG, Tiel RL. Peroneal intraneural ganglia: the importance of the articular branch. Clinical series. J Neurosurg 2003;99(2):319-29.
35. Stack RE, Bianco AJ Jr, MacCarty CS. Compression of the common peroneal nerve by ganglion cysts: report of nine cases. J Bone Joint Surg Am 1965;47:773-8.

36. Styf J. Entrapment of the superficial peroneal nerve. Diagnosis and results of decompression. J Bone Joint Surg $\mathrm{Br}$ 1989;71(1):131-5.

37. Styf J, Morberg P. The superficial peroneal tunnel syndrome. Results of treatment by decompression. J Bone Joint Surg Br 1997;79(5):801-3.

38. Woodhall $B$. The surgical repair of acute peripheral nerve injury. Surg Clin North Am 1951;31:1369-90.

39. Fabre T, Piton C, Andre D, Lasseur E, Durandeau A. Peroneal nerve entrapment. J Bone Joint Surg Am 1998;80(1):47-53.

40. Bahri H, Gomis R, Ascencio G, Allieu Y. Complications neurologiques des lésions post-traumatiqes de la cheville. In: Simon L, Rodineau J, editors. Cheville et médecine de réeducation. Collection de pathologie locomotrice. Paris: Ed Masson; 1982. p.170-5. 